\title{
Desemprego e (des)mobilização política no capitalismo contemporâneo
}

\author{
Eleonora Frenkel Barretto
}

O desemprego é hoje uma questão central nas economias capitalistas; centralidade esta que vem à tona dado o caráter mundial do fenômeno e suas dimensões: dados da OIT indicam que o número de desempregados ou subempregados chegou próximo aos 800 milhões, na década de 1990, dos quais cerca de 40 milhões nos chamados países de capitalismo avançado².

Nos países da OCDE, os índices de desemprego indicam um crescimento significativo do fenômeno ao longo da década, embora este movimento ascendente não seja homogêneo em todos eles ${ }^{3}$. No Brasil, em todas as regiões pesquisadas pelo DIEESE ${ }^{4}$, os índices de desemprego total de 1999 são mais altos que os índices de anos anteriores, com crescimento constante, ainda que com variações de intensidade ${ }^{5}$. Destacase também a complexidade que o fenômeno assume na atualidade, expressando-se

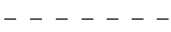

1 Mestre em Ciência Política pela Unicamp.

2 José Meneleu Neto. “Desemprego e luta de classes: as novas determinidades do conceito marxista de exército industrial de reserva". In: Teixeira, F. e Oliveira, M. (orgs.) Neoliberalismo e reestruturação produtiva. As novas determinações do mundo do trabalho. São Paulo: Cortez; Fortaleza: Universidade Estadual do Ceará, 1996, pp. 75- 107.

3 DIEESE. Anuário dos trabalhadores 2000-2001.São Paulo: DIEESE, 2001a, p. 127. 0 DIEESE fornece aqui dados de 11 países que compõem a OCDE: Alemanha, Espanha, França, Inglaterra, Itália, Suécia, Suíça, Japão, Portugal, Canadá e EUA. Segundo Meneleu Neto (1996: 100), a taxa média de desemprego para o conjunto dos 24 países da OCDE passou de $4 \%$ nos anos 1970 para 8,5\% nos anos 1990.

4 A saber: São Paulo, Belo Horizonte, Distrito Federal, Porto Alegre, Salvador e Recife.

5 DIEESE. A situação do trabalho no Brasil. São Paulo: DIEESE, 2001b, p. 51.

cadernos cemarx, $n^{0} 2-2005 \mid \mathbf{1 0}$ 
através de diversas situações que não são "detectadas" pelas taxas de desemprego aberto, como a inatividade, o desemprego de longa duração (12 meses ou mais), a subutilização da força de trabalho e a situação de desalento ${ }^{6}$.

Embora tenha adquirido hoje esta notoriedade, expressa em seus números alarmantes, é fundamental lembrar que o desemprego é intrínseco ao modo de produção capitalista, é necessário à sua reprodução, possui uma função dentro da lógica da acumulação capitalista. Não se trata, portanto, de um "problema recente", de um sintoma de "crise" do capitalismo; trata-se de um mecanismo próprio deste modo de produção para intensificar a exploração do trabalho e desmobilizar a classe trabalhadora, paradoxalmente, mediante a afirmação do caráter supérfluo da força de trabalho para a produção.

Marx desenvolveu em O Capital a "Lei geral da acumulação capitalista", segundo a qual o movimento do capital tende sempre à sua maior concentração e centralização, em oposição à pauperização crescente da classe trabalhadora. A criação do "exército industrial de reserva" é um mecanismo fundamental deste processo, resumido a seguir em linhas gerais. ${ }^{7}$

A acumulação de capital possibilita o desenvolvimento do modo de produção capitalista e gera seu pressuposto, mais acumulação de capital. Com isto, há uma concentração crescente dos meios de produção e do comando sobre o trabalho em mãos de capitalistas individuais. "O crescimento do capital social realiza-se no crescimento de muitos capitais individuais" ". Mas isto cria, ao mesmo tempo, uma repulsão recíproca entre capitais individuais concorrentes.

$-\cdots$

6 Cláudio S. Dedecca. “Desregulação e desemprego no capitalismo avançado". In: São Paulo em Perspectiva, vol. 10, n.1, jan.-mar. 1996, pp. 13-20.

7 Não abordarei aqui a primeira fase deste processo, na qual os salários são regulados pelo aumento ou redução do exército industrial de reserva: com a acumulação de capital, parte deste destina-se ao incremento do capital adicional, ampliando a necessidade de força de trabalho e gerando um aumento dos salários; mas, quando os salários aumentam, reduz-se a acumulação, reduz-se o incremento do capital adicional e, portanto, diminui a necessidade de força de trabalho, provocando uma redução dos salários. Ou seja, o próprio mecanismo do processo de produção capitalista elimina os empecilhos que cria temporariamente: se, com o aumento dos salários, há uma diminuição da acumulação, há uma diminuição do incremento de capital adicional e, portanto, da necessidade de força de trabalho; desaparece, assim, a desproporção entre capital e força de trabalho explorável. Deste modo, "O preço do trabalho cai novamente para um nível correspondente às necessidades de valorização do capital" (Karl Marx. "A lei geral da acumulação capitalista". In: O Capital.

SP: Nova Cultural, 1988, vol. 1, Livro Primeiro, Tomo 2, capítulo XXIII, p. 183).

8 Marx, op. cit., p. 187.

108 Desemprego e (des)mobilização política no capitalismo contemporâneo 
Esta etapa da acumulação e da concentração é seguida pela centralização propriamente dita: a atração de capital por capital, "expropriação de capitalista por capitalista, transformação de muitos capitais menores em poucos capitais maiores" capitais derrotam os pequenos na concorrência, pois conseguem oferecer menores preços por terem maior produtividade, por terem uma maior escala de produção.

Enquanto a centralização reforça e acelera os efeitos da acumulação, amplia e acelera simultaneamente as revoluções na composição técnica do capital, que aumentam sua parte constante à custa de sua parte variável e, com isso, diminuem a demanda relativa de trabalho. Assim, a proporção da parte variável do capital decresce continuamente e inversamente ao crescimento da grandeza do capital.

Surge, então, como produto deste movimento do capital uma população excedente, aparentemente desnecessária, mas, na realidade, fundamental para o processo de acumulação; inicialmente porque está disponível para ser explorada a qualquer momento em que o capital adicional seja lançado em novos ramos produtivos; mas, acima de tudo, porque permite a intensificação da exploração do trabalho daqueles que se mantêm ocupados:

O sobretrabalho da parte ocupada da classe trabalhadora engrossa as fileiras de sua reserva, enquanto, inversamente, a maior pressão que a última exerce sobre a primeira obriga-a ao sobretrabalho e à submissão aos ditames do capital. A condenação de uma parcela da classe trabalhadora à ociosidade forçada em virtude do sobretrabalho da outra parte e vice-versa torna-se um meio de enriquecimento do capitalista individual e acelera, simultaneamente, a produção do exército industrial de reserva numa escala adequada ao progresso da acumulação social ${ }^{10}$.

O processo de acumulação capitalista intensifica a submissão do trabalhador através da criação dessa superpopulação relativa aparentemente desnecessária para a produção. O trabalhador empregado se vê obrigado a submeter-se plenamente às condições de trabalho impostas, aumentando a produtividade e contribuindo para a criação de sua própria redundância relativa, na medida em que possibilita que mais trabalho seja extraído com menos trabalhadores empregados.

$-\cdots-\cdots$

9 Idem. Ibidem.

10 Idem, p. 194.

cadernos cemarx, $n^{0} 2-2005 \quad 109$ 
O que procuramos destacar aqui é que o controle do emprego é um elemento decisivo da relação de força que se trava entre capital e trabalho, de modo que as flutuações dos níveis de emprego e desemprego não podem ser entendidas sem questionar suas implicações políticas. Não devemos nos enganar com a idéia do desemprego como problema de desajuste do capitalismo ou como sintoma de seu mau funcionamento. Devemos pensar a função política do fenômeno no processo de acumulação capitalista e compreender a atualização da luta de classes que expressa. É nestes termos que é preciso questionar o papel do desemprego na reestruturação do capital em curso. Como coloca Meneleu Neto ${ }^{11}$, urge a necessidade de repensar o conceito de Exército Industrial de Reserva (EIR), perguntando "qual é o seu papel na definição das novas estratégias do capital e do trabalho?".

O desemprego é um poderoso instrumento do capital para desmobilizar a classe trabalhadora, uma vez que o medo do desemprego obriga o trabalhador a se submeter a qualquer condição de trabalho e inibe a participação política; além disto, a competitividade entre os trabalhadores mina a capacidade de reivindicação coletiva. Como afirma Costa, "o capital amplia seu poder com a retração da organização sindical em função da ameaça sempre presente do desemprego"12.

Isto é bastante claro na incapacidade da classe trabalhadora de resistir à imposição das políticas neoliberais e da reestruturação produtiva no atual processo de renovação da economia capitalista. Com o aumento do EIR, a classe trabalhadora tem sua capacidade de resistência enfraquecida e o capital retoma o controle sobre o ritmo e a modalidade do processo de trabalho, impondo a desregulamentação das relações de trabalho e o novo padrão de gestão produtiva.

Para compreender esta formulação, é preciso relacionar este processo de renovação da economia capitalista com a crise do modelo fordista de acumulação. Resumidamente, esta última leva à crise de rentabilidade do capital e à presença de condições institucionais desfavoráveis a uma maior exploração da força de trabalho, leia-se, um sindicalismo organizado e um Estado interventor. Para retomar o ciclo de valorização do capital, era preciso remover o poder de resistência dos trabalhadores às tentativas de intensificação do ritmo de trabalho e, para tanto, era preci-

$---\cdot-$

110 p. cit., p. 77.

12 Márcia da Silva Costa. Despotismo de mercado. Medo do desemprego e relações de trabalho em contexto de reestruturação produtiva brasileira dos anos 90. Tese de doutorado, IUPERJ. Rio de Janeiro: 2002, p. 8.

110 Desemprego e (des)mobilização política no capitalismo contemporâneo 
so desregulamentar o quanto possível a economia, colocando em prática uma nova política econômica. A reestruturação do poder do capital passa, portanto, a ter como requisito a fragilização dos sindicatos. O desemprego entra aí como uma maneira conveniente de reduzir a força da classe operária ${ }^{13}$.

É neste sentido que Beynon, falando a respeito das ações governamentais de Thatcher na Inglaterra, durante a década de 1980, afirma que

Aumentar o desemprego foi uma maneira muito conveniente de reduzir a força da classe operária [...] o que se procurou forjar - para falar numa linguagem marxista - foi uma crise no capitalismo, que repôs o exército industrial de reserva e permitiu aos capitalistas a obtenção de grandes lucros daí por diante ${ }^{14}$.

Ou seja, a política econômica neoliberal repôs o EIR, com o objetivo de retomar a autonomia do mercado frente ao poder do trabalho organizado e de recuperar o grau de liberdade perdido durante a vigência do Estado de bem-estar social. ${ }^{15}$

Este ajuste neoliberal do mercado de trabalho é acompanhado pelo processo de reestruturação no chão de fábrica, traduzido pela introdução de novas tecnologias poupadoras de força de trabalho e pela adoção de modelos japoneses de gestão que estimulam o individualismo e a competição interna à força de trabalho. O medo do desemprego tem aí o papel estratégico de obter uma maior disciplina do trabalhador e de facilitar a adesão à ideologia da cooperação na empresa, minando, uma vez mais, sua capacidade reivindicativa ${ }^{16}$.

É importante destacar, contra a naturalização do fenômeno do desemprego promovida pelas idéias de inevitabilidade e positividade do avanço tecnológico, bem como de submissão da sociedade às forças cegas do mercado, que os níveis

$-\cdots-\cdots$

13 Cf. Meneleu Neto, op. cit.

14 Beynon, 1995, Apud, Meneleu Neto, op. cit., p.78.

15 É importante lembrar que esta análise tem como modelo a Inglaterra e países da Europa ocidental onde 0 Estado de bem-estar social se consolidou. A análise do problema nos países capitalistas periféricos tem suas especificidades, a começar pelo fato de que não tiveram um Estado de bem-estar social estruturado, de que o leque de direitos sociais conquistados é menos amplo, que não se atingiram os mesmos níveis de emprego e que a capacidade de resistência da classe trabalhadora é inferior, com um sindicalismo menos estruturado. 16 cf. Meneleu Neto, op. cit. e Costa, op. cit.

cadernos cemarx, $n^{0} 2-2005 \mid \mathbf{1 1} 1$ 
de emprego podem ser controlados pelas classes dominantes,

Por meio de estratégias como a implementação de uma política recessiva, de uma política de inovação tecnológica ou de uma política de reengenharia organizacional (que difunda a terceirização em todos os níveis, que faça aumentar o contingente de trabalhadores formalmente autônomos e sujeitos de fato a empresas determinadas, que incentive o apelo ao trabalho precário etc. $)^{17}$.

Isto, sempre que a capacidade de resistência da classe trabalhadora ameace seus interesses políticos e econômicos. E é nesse sentido que, ao pensar o desemprego, deve-se pensar na primazia da luta de classes sobre os ditos "fatores objetivos" da economia, nos quais se apóia a naturalização do fenômeno. Ao contrário de algo natural ou inevitável, o desemprego é um fator por excelência de enfraquecimento da resistência da classe trabalhadora ${ }^{18}$.

Ao questionar o desemprego como recurso político do capital para submeter, desmobilizar, enfraquecer a classe trabalhadora e desimpedir o livre desenvolvimento do processo de acumulação, apresenta-se, à classe trabalhadora, o desafio de lutar contra este fenômeno. Para tal, é preciso superar, inicialmente, o discurso da naturalização do desemprego e a idéia de que "não há saída contra as tendências inevitáveis do fim do operariado, do trabalho organizado, dos sindicatos, enfim, da luta de classes"19.

É necessário ter em mente, também, que a luta contra o desemprego nos limites do modo capitalista de produção, ou seja, restrita às reivindicações por políticas econômicas que visem a criação de novos postos de trabalho e por uma reforma dos sistemas do Estado de bem-estar social que se adaptem à "nova configuração" do mercado de trabalho, não rompe com a lógica da acumulação capitalista e, portanto, não elimina a possibilidade histórica de uma nova desestruturação das eventuais conquistas da classe trabalhadora neste sentido.

O desmonte do Estado de bem-estar social europeu é, mais uma vez, um bom exemplo: durante o período de vigência do chamado pleno emprego, a classe traba-

$-\cdots-\cdot-$

17 Décio Saes. "Cidadania e capitalismo: uma crítica à concepção liberal de cidadania". In: Crítica Marxista no. 16, 1 ạ edição . São Paulo: Editora Boitempo, 2003, pp. 09-38. Citação retirada da p. 37.

18 Meneleu Neto, op. cit., p. 81.

19 Idem, p. 76.

112 Desemprego e (des)mobilização política no capitalismo contemporâneo 
lhadora conquistou, mediante intensa luta e contra grande resistência das classes dominantes, a extensão de seus direitos sociais; isto representava para estas últimas um dos "perigos da cidadania", o que fica claramente demonstrado pela atual conjuntura, onde "os segmentos mais poderosos das classes dominantes aumentaram a sua potência de fogo no ataque ao Welfare State"20. Esta operação de destruição dos direitos sociais demonstra justamente o caráter reversível que estes têm no capitalismo; por não serem direitos essenciais, necessários à reprodução deste modo de produção, podem ser revertidos sempre que a correlação de forças for favorável às classes dominantes.

Deste modo, o grande desafio da classe trabalhadora está justamente em realizar algo já sugerido por Marx em O Capital: "organizar uma atuação conjunta planejada dos empregados com os desempregados para eliminar ou enfraquecer as ruinosas conseqüências daquela lei natural da produção capitalista sobre sua classe"21.

20 Saes, op. cit., p. 19

21 Marx, op. cit., p. 197.

cadernos cemarx, nำ2-2005 113 